\title{
THE USE OF URODYNAMIC STUDIES TO ASSESS THE EFFECT OF PHARMACOLOGICAL AGENTS WITH PARTICULAR REFERENCES TO ALPHA-ADRENERGIC BLOCKADE
}

\author{
By D. G. Thomas, F.R.C.S., N. H. Philp, F.R.C.S., T. E. D. McDermott, \\ F.R.C.S. (I) and A. M. K. Rickwood, F.R.C.S. \\ Spinal Unit, Lodge Moor Hospital, Sheffield Io, U.K.
}

Summary. A method of studying the effect of drugs on the lower urinary tract is described, using cord-injured patients with detrusor hyperreflexia. In this study I9 patients received intravenous phentolamine. This alpha-adrenergic blockade produced a significant reduction in the maximum voiding detrusor pressure, voided volumes and peak flow rates with no reduction of outflow tract obstruction.

Key words: Paraplegia; Reflex micturition; Urodynamics; Phentolamine; Alphaadrenergic blockade.

\section{Introduction}

CombINED urodynamic and radiological studies of the lewer urinary tract are now accepted as routine investigations in patients with neuropathic bladder dysfunction. Accurate and objective studies of lower tract dysfunction lead to precise methods of clinical management. This paper describes another aspect of the use of urodynamic studies, in the objective assessment of pharmacological agents.

The reflex bladder of the male patient with a suprasacral cord injury provides a useful dynamic model for the evaluation of drugs acting on the lower urinary tract. Previous work has detailed the method with studies on cholinergic drugs (Philp et al., I980). We describe the results of the effect of phentolamine on the voiding parameters in suprasacral cord-injured patients.

\section{Patients and Methods}

Nineteen male patients with complete suprasacral cord lesions were studied. All patients had well established reflex micturition with detrusor hyperreflexia. No patient was receiving any drug affecting the lower urinary tract.

The urodynamic system measures the subtracted detrusor pressure, voided flow rate and voided volume. Two small diameter catheters were passed trans-urethrally, one for bladder filling and the other for the measurement of bladder pressure with a fluid filled system and remote transducer (Fig. I). Both catheters were left in situ during voiding, so allowing repeated filling and voiding. The bladder was not emptied prior to the studies. The bladder was filled at a constant rate for each patient, the average being $20 \mathrm{mls}$ per minute. Using constant bladder filling, repeated voiding sequences were recorded until the pattern of voiding became regular and reproducible (Fig. 2). Once this regular pattern was established each patient 


\section{Diagram of combined video-urodynamic studies}

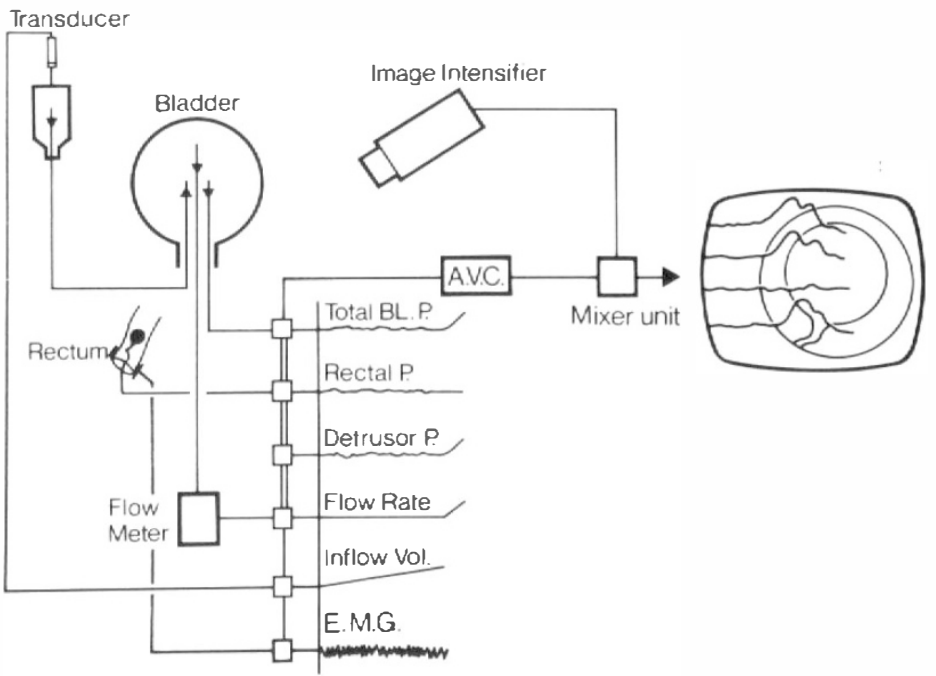

FIG. I

Diagram of urodynamic/radiological system.

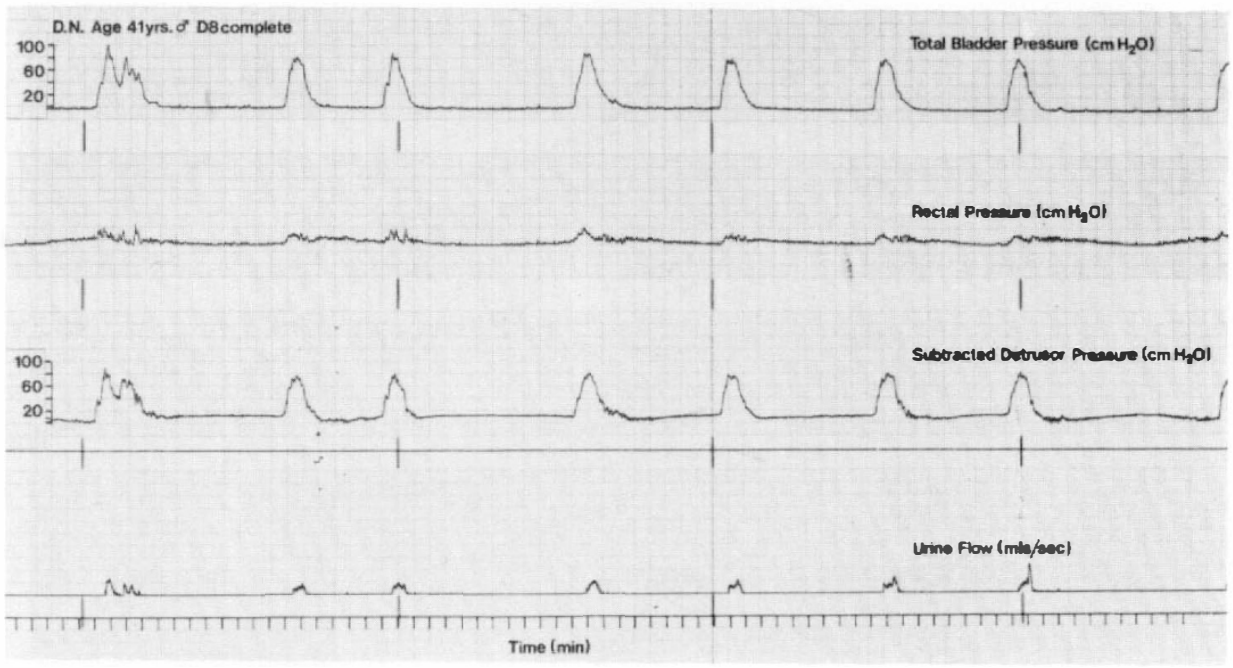

FIG. 2

Urodynamic data from male patient with D.5. (complete) paraplegia. Regular and reproducible pattern of voiding.

received a constant intravenous infusion of the alpha-adrenergic blocking agent phentolamine mesylate at a dose of I $\mathrm{mg}$ per minute. Further recordings of voiding were recorded during phentolamine infusion with a minimum of three voiding sequences: 
The following parameters were studied: maximum detrusor pressure, length of detrusor contractions, the interval between detrusor contractions, voided volumes, peak flow rates and the initial isometric detrusor pressure rise, an index of detrusor-sphincter dyssynergia.

\section{Results}

Although several voiding sequences were recorded, the results are expressed as an average for each parameter before and during alpha-adrenergic blockade. The only significant changes in the recorded parameters occurred as a decrease in maximal detrusor pressures $(\mathrm{p}<0.002)$ (Fig. 3), a fall in voided volumes $(\mathrm{p} \bumpeq 0.05)$ (Fig. 4) and peak flow rates $(\mathrm{p}<0.025)$ (Fig. 5). The most significant change was the decrease of maximum detrusor pressure.

There was no significant change in the length of detrusor contractions, the interval between contractions or the degree of initial dyssynergia.

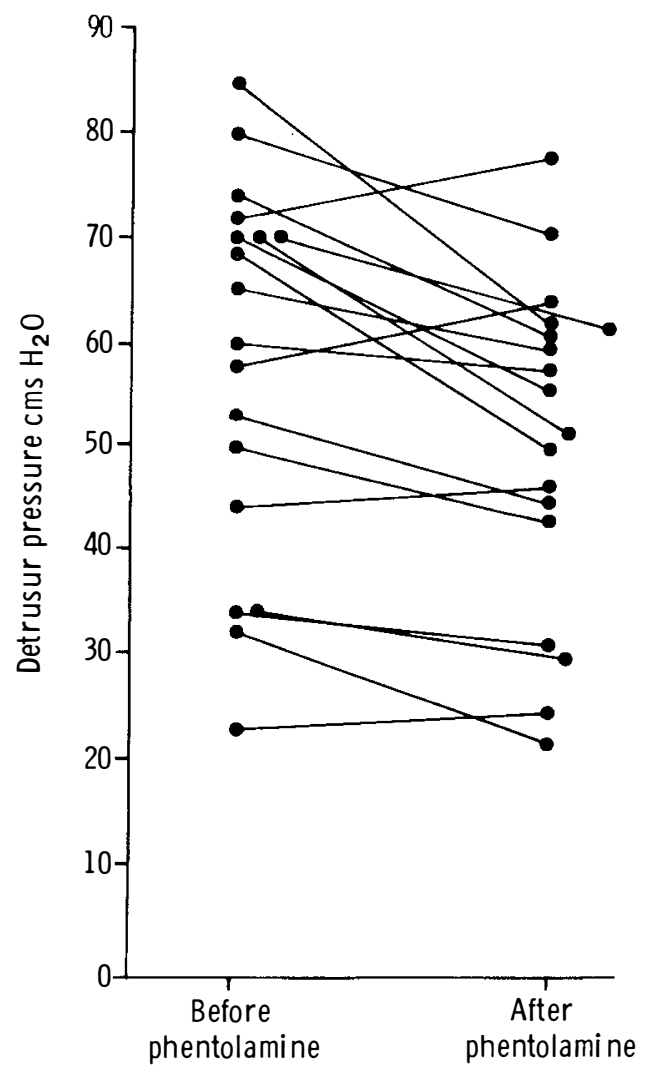

FIG. 3

The change in maximum detrusor pressure with phentolamine $(\mathrm{p}<0.002)$. 


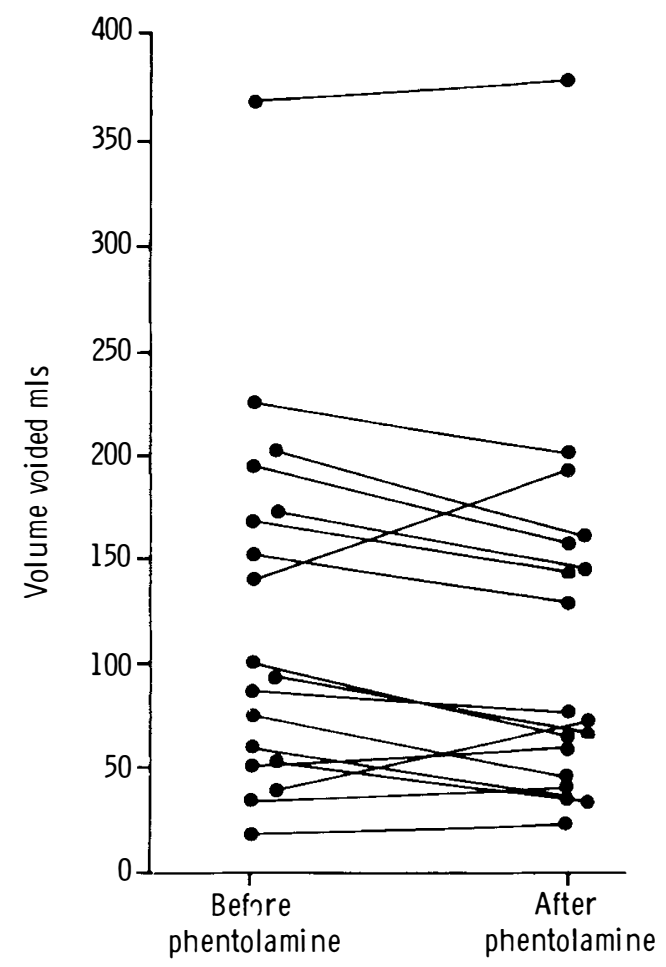

FIG. 4

The change in voided volumes with phentolamine $(p \bumpeq 0.05)$.

\section{Discussion}

Alpha-adrenergic blocking drugs are reported to reduce the resistance to voiding by their action at the bladder neck and proximal urethra. Clarke and co-workers showed that adrenergic blockade reduces the distal urethral sphincter pressure as measured with the urethral pressure profile in patients with conus and cauda equina lesions (Clarke and Thomas I98I).

Mobley (I976) claimed that oral phenoxybenzamine was of value in all types of neuropathic bladder dysfunction, including patients with reflex micturition. Similarly Olsson and colleagues (1977) reported improved voiding as judged by flow measurements in six patients out of I I with upper motor neurone lesions. Conversely, Hachen (1980) reported the value of phenoxybenzamine in improving voiding in patients with autonomous bladders but with no effect in those with automatic bladders. In vitro studies of human detrusor strips have shown that phentolamine resulted in the inhibition of an electrically evoked response. This inhibition was significantly greater in muscle obtained from patients with detrusor instability (Eaton and Bates 1982).

The results of this present study supports the in vivo work of Eaton, namely that phentolamine produces an inhibitory effect on the detrusor 


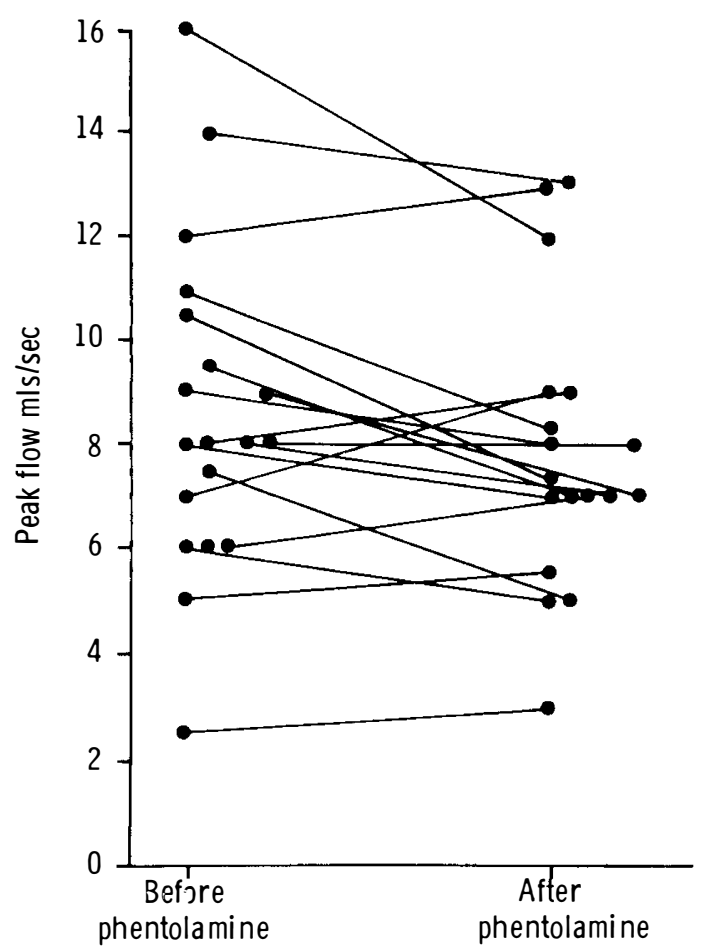

FIG. 5

The change in peak flow rates with phentolamine $(\mathrm{p}<0.025)$.

with consequent reduction in flow rate in patients with detrusor hyperreflexia.

There was no evidence of a reduction in outlet resistance or change in detrusor-sphincter dyssynergia.

\section{RÉSUMÉ}

Une methode d'étudier l'esset des drogues sur la vessie est decrivée utilisant des blessés du cordon medullaire avec hyperreflexia detrusor. Dans cette étude 19 malades etient donné phentolamine intra-veineux. Phentolamine provoqué une reduction significatis dans la pressions detrusor maximum en vidant torrents vidé, et pointe écoulement mais il n'y a pas une reduction de écoulement tract encombrement.

\section{ZUSAMMENFASSUNG}

Wir beschreiben eine Methode die Wirkung von Medikamenten auf den unteren Harnapparat in Rückenmark-Beschädigten mit Hyperreflexie des Detrusor muskels zu bewerten. I9 Patienten erhielten Phentolamin intravenös. Dieser Ganglionblocker verursachte eine signifikante Reduktion in maximalen Detrusordruck, im Urinausscheidungsvolumen und in Hockpunkt der Ausscheidungsgeschwindigkeit, ohne Minderung in der Obstruktion der Harnwege. 


\section{REFERENCES}

Clarke, S. J. \& Thomas, D. G. (I98I). Characteristics of the urethral pressure profile in flaccid male paraplegics. Brit. F. Urol., 53, I57-I6I.

Eaton, A. C. \& BAtes, C. P. (I982). An in vitro physiological study of normal and unstable human detrusor muscle. Brit. F. Urol., 54, 653-657.

HACHEN, H. J. (1980). Clinical and urodynamic assessment of alpha-adrenolytic therapy in patients with neurogenic bladder function. Paraplegia, 18, 229-238.

Mobley, D. F. (1976). Phenoxybenzamine in the management of neurogenic vesical dysfunction. F. Urol., II6, 737-738.

Olsson, C. A., Siroky, M. B. \& KRANE, R. J. (1977). The phentolamine test in neurogenic bladder dysfunction. F. Urol., II 7, 48I-485.

Philp, N. H., Thomas, D. G. \& Clarke, S. J. (I980). Drug effects on the voiding cystometrogram: a comparison of oral bethanecol and carbachol. Brit. F. Urol., 52, 484-487. 